\title{
¿POLÍTICA DE LA NATURALEZA O LA NATURALEZA COMO POLÍTICA? CLAVES TEÓRICAS PARA REPENSAR LA RELACIÓN DE NATURALEZA Y CULTURA
}

\begin{abstract}
Sascha Miguel Cornejo Puschner ${ }^{1}$
Andrés Juan Duran Pereira ${ }^{2}$

Resumen/Abstract

Las transformaciones en el ámbito de la ciencia y la tecnología han generado otros modos de concebir la naturaleza. A tal punto que en la actualidad coexisten distintos modos de comprenderla. Esta proliferación de discursos, promovidas desde distintas esferas de la actividad humana, conlleva la necesidad de problematizar este concepto en función de los diferentes usos a los cuales está sometido. Disciplinas como la antropología, la ecología política y los estudios sociales de ciencia y tecnología han entrado en un espacio de discusión que deja en evidencia que la naturaleza se ha transformado en un asunto político, no sólo desde el punto de vista ecológico sino también conceptual y semiótico.
\end{abstract}

Palabras claves: naturaleza, cultura, tecnología, ciencia, modernidad, ecología política, antropología

\section{POLITICS OF NATURE OR NATURE AS POLITICS? THEORETICAL KEYS TO RE-THINK THE RELATIONSHIP OF NATURE AND CULTURE}

Scientific and technological progress has been transforming the way humans understand nature. Consequently, many and different approaches to nature coexist these days. Different dimensions of human activity promote such variety of discourses. These ones lead us to problematize the already modified concept of nature and its function in different human contexts. Anthropology, political ecology and social studies on science and technology have discussed what nature is. They have agreed that it has turned into a political issue; not only from the ecological but also from the conceptual and semiotic perspectives.

Keywords: nature, culture, technology, science, modernity, political ecology, anthropology

${ }^{1}$ Chileno. E-mail: scornejopuschner@gmail.com

${ }^{2}$ Chileno. E-mail: aduranp@docentes.academia.cl 


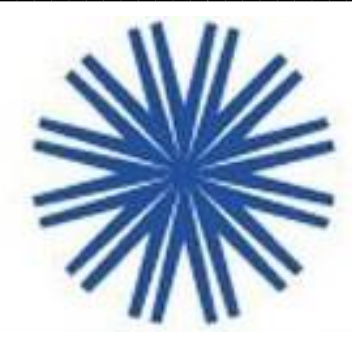

\section{Introducción: La naturaleza como problema político-teórico}

A pesar de la emergencia de la relación entre el ser humano y la naturaleza como un eje problemático, el concepto de "naturaleza" ha demostrado cierta resistencia a la deconstrucción teórica de estas últimas décadas. ${ }^{3}$ Aunque conceptos como "sujeto", "ciencia", "política", "modernidad" y "posmodernidad" han sido permanentemente problematizados en diferentes contextos del pensamiento contemporáneo, esto ha ocurrido en menor medida con la noción de "naturaleza". En este sentido no es infructuoso preguntar sobre el porqué de esta especie de "resistencia" a la interrogación. Todo parece indicar que la denominación "naturaleza" se sigue entendiendo como algo "exterior" a los asuntos humanos y desde allí, comprendida como una entidad dada, pasiva o inerte.

Sin embargo, y a pesar de lo anterior, se pueden vislumbrar algunos intentos de abordaje crítico a partir de ciertas áreas de estudio, perspectivas que nos invitan a formularnos algunas preguntas al respecto: ¿por qué el concepto de naturaleza dista tanto de ser reconocido como un discurso más entre muchos otros? Así como existe un discurso que ha problematizado al sujeto, a la modernidad, la tecnología o la ciencia ¿acaso no existe a su vez un discurso "sobre" la naturaleza que sostiene gran parte de nuestras creencias sobre ella? Es factible sostener que problematizar el discurso sobre la naturaleza implicaría interrogar y poner en duda un sostén teórico que parece incuestionable hasta nuestros días ${ }^{4}$. ¿Quién osaría en dudar de la existencia de una "naturaleza"? ¿Podríamos formular la idea, acaso, de que existe una diversidad de "naturalezas"? ¿Cómo es posible fundamentar teóricamente la emergencia de esta problematización? He aquí el desafío del presente artículo.

\footnotetext{
${ }^{3}$ Se ocupa acá "de-construcción" no en el sentido derridiano sino más bien como sinónimo de "problematización” y discusión teórica.

${ }^{4}$ Habrá que mencionar algunas tentativas de-constructivas de este término en los trabajos de Lewis y Lewontin, que cuestionan, desde la dialéctica, la serie de planteamientos teóricos que ha suscitado la naturaleza desde la constitución del evolucionismo como teoría fundante de la biología moderna y la consecuente despolitización de la naturaleza como efecto ideológico del cientificismo moderno (Lewis \& Lewontin, 2009). A su vez los trabajos más tardíos de Bruno Latour (2010) en los cuales el autor analiza las políticas de la naturaleza desplegadas en la modernidad, tales como el ecologismo, pero que siguen estando ancladas en el efecto de separación de ésta con la cultura humana; las críticas aún más radicales de Swyngedouw (2001) acerca de la naturaleza como el lugar del "significante vacío", la proyección incesante de nuevas fantasías y la permanente (y paradójica) despolitización de ella. Su tesis sigue a Zizek en que "la naturaleza no existe" y que es fuente permanente de fantasías proyectadas sobre ese lugar que permanece en la indistinción máxima, como es el lugar de la naturaleza. También están las críticas en el ámbito de la teoría literaria, de Timothy Morton que apuntan al ecologismo crítico y su permanente evocación de una naturaleza "romantizada" que ha acompañado gran parte de las fantasías literarias de la modernidad y que aún permanece en el núcleo duro del ecologismo actual. Su crítica apunta sobre todo a este núcleo del ecocriticismo y fundamento epistemológico enraizado en el concepto de naturaleza (Morton, 2007). En realidad, lo que podemos apreciar al respecto es una verdadera disputa por el significado que es posible atribuir a la idea de "naturaleza", disputa que no se remite sólo al ámbito intelectual sino, como veremos, también al político.
} 
Contextualización y emergencia de un problema: la interrogación por la vinculación entre "desarrollo" y "naturaleza"

Como tesis preliminar sostendremos que quién desee abordar esta temática deberá proceder de forma transdisciplinaria, ya que el concepto de naturaleza ha comenzado a ser tematizado de forma parcelada en diversos contextos de estudio, como es la ecología política (Leff 2003; 2004), los estudios sociales de la ciencia y tecnología (Latour 2007; Knorr-Cetina 2002; Shapin \& Shaffer 1985), así como también, en la antropología cultural (Descola 2013; 2014).

Es de suponer que este emergente contexto teórico posee cierto grado de correspondencia con la situación ecológica que vive nuestro planeta, lo que conlleva la necesidad de repensar nuestra relación en el mundo que habitamos. Esta situación se encuentra sobre todo forzada por la preocupación medioambiental en relación al desarrollo económico. Ya hace algunas décadas que ha tomado forma la preocupación ecológica como un discurso medioambiental fuertemente constituido desde las diversas cumbres que se han celebrado en el mundo desde el año $1972^{5}$. Sin embargo, no todos los discursos ecológicos se sitúan en la esfera hegemónica del discurso político ${ }^{6}$. Para algunos autores, la crítica del ecologismo debe integrar a su vez la crítica a las políticas económicas promovidas, por ejemplo, desde el Banco Mundial o el FMI (Leff 2003; Duran 2011). Sin embargo, se ha argumentado bastante que estos poderes transnacionales son los que hoy promueven la ideología del desarrollo sostenible, a partir de una aparente preocupación de la ecología planetaria, por el calentamiento global, la merma de los recursos energéticos no-renovables, las alternativas energéticas, la biodiversidad, entre otros factores. Ante estos escenarios, es evidente el hecho que la ecología se ha transformado en un asunto político ${ }^{7}$ que merece ser atendido en función de los

\footnotetext{
${ }^{5}$ Se estima que la "Cumbre de la Tierra" celebrado en la ciudad de Estocolmo fue una de los primeros encuentros, donde se puso en discusión la importancia sobre las políticas medioambientales promovidas por la ONU.

${ }^{6}$ Con "discurso hegemónico" nos referimos ante todo a las promociones medioambientales del Banco mundial y el FMI, basadas en la noción de "desarrollo sustentable" concepto que aparece mencionado por primera vez en el Informe de Bruntland et all (1987).

${ }^{7}$ El clamor biopolítico se ha ido filtrando en el discurso de las Naciones Unidas, donde la naturaleza es concebida como "medio ambiente" o también como "ecosistema", cuyo cuidado y protección resulta indispensable para la salud de la vida y la vida de nuestra especie. Por ejemplo en la Declaración de Rio sobre el medio ambiente y el desarrollo, se establece toda una normativa a la cual deben plegarse los estados miembros respecto al cuidado del medio ambiente, la sustentabilidad de las políticas económicas y la paz. Versa así en el principio 7: "Los Estados deberán cooperar con espíritu de solidaridad mundial para conservar, proteger y restablecer la salud y la integridad del ecosistema de la Tierra. En vista de que han contribuido en distinta medida a la degradación del medio ambiente mundial, los Estados tienen responsabilidades comunes, pero diferenciadas."
} 
contextos teóricos que hoy remecen nuestros fundamentos epistemológicos ${ }^{8}$, por lo menos en lo que respecta nuestra moderna comprensión acerca de la relación entre cultura y naturaleza.

Esto significa que ya no podemos desligar nuestra comprensión de la "naturaleza" de nuestra práctica económica y política con la cual configuramos nuestra relación hacia ella, vale decir, la práctica económica basada en los conceptos de productividad y crecimiento (Quiroga 1990; 2003). Es tema de debate si la crisis ecológica que hoy experimentamos es producto o no del permanente "desarrollo" de políticas económicas capitalistas ${ }^{9}$, aunque todo parece indicar que esto es así. Ahora bien, el discurso ecológico sostenido en la actualidad, sobre todo por entidades transnacionales como Naciones Unidas, el FMI y el Banco Mundial, insiste, por un lado, en argumentar sobre la importancia de tender hacia el desarrollo y el crecimiento económico como principales motores del progreso de nuestra civilización, mientras que, por el otro, aboga por el proteccionismo de la naturaleza, desde donde debiera ser preservada mediante nuevas formas de productividad económica ${ }^{10}$. Eso es al menos lo que la visión hegemónica intenta consolidar: la explotación productiva de la naturaleza con la tendencia creciente de la preservación de ella (Leff 2004; Smith 2007). Lo que muestra la discusión contemporánea al respecto, es que los

\footnotetext{
${ }^{8}$ Con "fundamentos epistemológicos", nos referimos a la creciente sospecha, emanada de los STS y de la ecología política, que la institución humana que configura el sistema de conocimientos que es la ciencia, no puede proporcionar un saber cien por ciento seguro ni certero ante un mundo cada vez más cambiante y complejo. Esto lo demuestran sobre todo las lecturas más históricas de la epistemología como las de Kuhn que enfatiza en los cambios de paradigma más que en las permanencias. Lo que no significa que habrá que desechar a la ciencia como sistema de conocimientos constituidos bajo ciertas reglas, sino que enriquecer su punto de vista, quizás tomando en cuenta otras lecturas y formas de conocer antes no incluidas en su campo de estudio. Sin duda que en este sentido, la etnología tiene mucho de aportar.

${ }^{9}$ Quizás el Informe del club de Roma, Los límites del crecimiento, es uno de los ejemplos más ilustrativos de esta discusión. El informe daba una visión pesimista de la economía mundial, mezclado con elementos postmalthusianos, advertía hace cerca de 40 años que el planeta a la larga no podría soportar el ritmo de explotación llevado hasta ese entonces y que el desequilibrio entre la producción alimenticia y aumento de la población mundial era inminente. En el año 2004 se publicó una actualización del estudio que confirman los diagnósticos de 1972, así también en 2012.

${ }^{10}$ Para dar cuenta de ello conviene revisar las declaraciones de las diferentes cumbres medioambientales celebradas durante ya varias décadas. Por ejemplo, la "Declaración de Johanesburgo sobre el desarrollo sostenible", sostiene en el $5^{\circ}$ parágrafo: “...asumimos la responsabilidad colectiva de promover y fortalecer en los planos local, nacional, regional y mundial, el desarrollo económico, desarrollo social y la protección ambiental, pilares interdependientes y sinérgicos del desarrollo sostenible". A su vez, la "Declaración de Rio sobre el medio ambiente y el desarrollo" (Rio +10$)$ dice en el $4^{\circ}$ parágrafo: "A fin de alcanzar el desarrollo sustentable, la protección del medio ambiente deberá constituir parte integrante del proceso de desarrollo y no podrá considerarse en forma aislada". Más adelante señala, respecto a la función de los Estados: "Los Estados deberán cooperar en la promoción de un sistema económico internacional favorable y abierto que llevara el crecimiento económico y el desarrollo sustentable de todos los países, a fin de abordar en mejor forma los problemas de la degradación ambiental." Tal como lo analiza el economista Roberto Bermejo en su análisis del informe Brundtland, el problema de las políticas ecológicas que se han propuesto, reside en seguir sosteniendo un desarrollo basado en el crecimiento ilimitado, lo que desde el punto de vista científico no es sostenible a largo plazo. Todo parece indiciar que el concepto de Desarrollo Sostenible ha tenido transformaciones de sentido que han entorpecido enormemente la implementación de políticas reales y efectivas, así como también se ha alejado de sus formulaciones originales sostenidas en el informe Bruntland. Por otra parte, los trabajos sobre el Postdesarrollo de Arturo Escobar conducen a una crítica radical hacia el mismo concepto de desarrollo, que configuró gran parte de las políticas económicas de las naciones latinoamericanas.
} 
discursos hegemónicos en perspectiva ecológica se sitúan en medio de una importante contradicción: intentar dar sostenibilidad al mundo en que vivimos, pero profundizando una relación hacia él en que lo predominante es tender hacia una productividad que sólo genera acumulación de capital. Lo que desde este discurso técnico político se denomina “desarrollo" y que se sostiene sobre la idea de la protección de la naturaleza, se presenta entonces como un dispositivo contradictorio toda vez que intenta remediar el problema con aquello que lo provoca.

En este marco de consideraciones, no podemos negar que la "naturaleza" se encuentre inexorablemente unida a la historia humana, y con esto, que la separación moderna entre naturaleza y cultura merece ser problematizada. El dualismo ontológico muestra signos de crisis y en especial, los conceptos de "naturaleza" y "cultura" han entrado a un espacio y un tiempo que exige volverlos a pensar en función de nuevas perspectivas, no sólo epistemológicas o metodológicas sino, sobre todo, ontológicas y existenciales, que signifiquen nuevos modos de convivir, representar, ser y exigir responsabilidad ante el mundo que habitamos (Jonas 1984; Serres 2004).

\section{La naturalización moderna de la "naturaleza"}

La comprensión de la naturaleza tiene un fundamento ontológico en la razón científica aplicada al mundo. Es difícil concebir la idea de naturaleza sin al mismo tiempo pensar en el conocimiento filosófico y científico que la hizo posible. Desde Galileo, Descartes hasta Kant se trató de delimitar el espacio de la razón humana en función de un mundo cognoscible tanto teórica como empíricamente. En general, cuando hablamos de "leyes naturales" "11 nos referimos a un espacio semióticamente delimitado que denominamos "naturaleza", y que funciona a partir de sus propios mecanismos inherentes, independiente de toda voluntad humana. La historia de la modernidad está atravesada por esa separación implícita: por un lado, la naturaleza, relegada en un espacio "exterior" a la razón humana, pero no por ello impermeable a su control y dominio (como lo demuestra muy bien el desarrollo de la ciencia durante y después de la segunda guerra mundial); y por otro, el gran abanico de la historia humana que da cuenta de un proceso civilizatorio de constante adaptación sociocultural a las condiciones naturales que presenta el medio ambiente. La naturaleza, en este sentido, ha funcionado como una especie de garantía, que permite a su vez, sostener

\footnotetext{
${ }^{11}$ Según la RAE, la primera acepción que aparece asociada al término "leyes" es "Regla fija a la que está sometido un fenómeno de la naturaleza." (RAE revisado 29/05/2017).
} 
otras creencias fuertemente arraigadas en la razón moderna, como son el objetivismo científico y el realismo ontológico ${ }^{12}$.

A mediados del siglo XIX y principios de siglo XX la discusión sobre la relación naturaleza y cultura permeó gran parte del interés de biólogos y científicos sociales ${ }^{13}$. En plena modernidad la relación entre la cultura humana y la naturaleza fue concebida a modo de escisión y rompimiento. Una larga tradición de pensamiento filosófico, desde Rousseau (1982), Hobbes (2009), hasta Freud (2010) y Marcuse (1970 b.) da cuenta de esta preocupación que concierne a la definición de ser humano en relación a la naturaleza, pero siempre en oposición a ella ${ }^{14}$. La pregunta que nos dejan estos planteamientos, tan cargados de seguridad, dice relación con los factores históricos que propiciaron el surgimiento de esta relación ambivalente entre ser humano y naturaleza, vale decir, de la idea del dominio sobre la naturaleza. Según Leiss es posible rastrear esta idea ya en el cristianismo temprano, que se basó en algunos pasajes de la Biblia donde se expresa en la "palabra de Dios", el dominio del hombre sobre la tierra y todo lo que a ella pertenece (Leiss, 1974: 31). Probablemente esta configuración dualista ya presente en el imaginario cultural de Occidente, no tuvo mayores dificultades de cristalizarse en nuevas ontologías y luego, con el surgimiento de la ciencia, en una epistemología basada en la expresa separación del ser humano y el mundo.

Actualmente, dada nuestra situación geoambiental, en referencia al cambio climático, vemos que la naturaleza como fuente inagotable de energía y recursos y como entidad "exterior" a nuestra historia, comienza a ser cuestionada, sobre todo en relación a lo que concierne a su "separación” ontológica de la esfera humana, concepción propiamente moderna. Comienza a dar lugar la preocupación por la casa común que habitamos, plasmado en el concepto griego del Oikos (Sloterdijk 1999; 2016) En este sentido la crítica de Heidegger (2015) a la modernidad, a través de una inspección de los supuestos filosóficos (metafísicos) de la ciencia moderna, adquiere cierta relevancia, en la medida en que la separación entre

\footnotetext{
${ }^{12}$ Gran parte de la tradición epistemológica de la modernidad gira en torno a las nociones de objetivismo, realismo y naturalismo. Sin embargo, este artículo no se enfocará a discutir esta relación, sino más bien dar algunas pistas para problematizar la noción de naturalismo ya problematizado por ej. en los trabajos de Descola (2001) e Ingold (2000).

${ }^{13}$ Esto se refleja sobre todo en el racismo científico de Cesare Lombroso y la noción de atavismo, como también en la discusión entre eugenistas y antropólogos, sobre las facultades "naturales" de ciertas razas (Cornejo, 2017).

${ }^{14}$ En una conferencia titulada "El científico natural: mediador entre cultura y naturaleza", el físico alemán Carl Friedrich von Weizsäcker (1982), problematiza la relación del científico con la naturaleza. La conferencia comienza con la formulación de la pregunta si acaso el científico es "mediador" o es "enemigo" de la naturaleza. De alguna forma esta ambivalencia de la relación del hombre moderno con la naturaleza deja abierta esa posibilidad: En este sentido, el control sobre la naturaleza implica una relación de dominio y por ende, también de enemistad.
} 
subjektum e imagen del mundo, también implica un particular modo de convivencia con ese mundo ${ }^{15}$. Esto significa que nuestra comprensión de la naturaleza está atravesada por nuestros particulares modos de enfrentarla e incorporarla a nuestra cultura.

Ante esto, la incipiente ecología política actualmente amalgama una profunda crítica al pensamiento moderno. Desde autores latinoamericanos como Enrique Leff o Arturo Escobar, podemos entender que para comprender nuestra modernidad y la actual crisis de sentido que vivimos ${ }^{16}$, ya no es posible separar la ciencia de la ecología o la política de la ciencia, y que, para generar una crítica a los supuestos metafísicos de la modernidad, no solo se debe interrogar el modo de apropiación capitalista de la naturaleza, sino que también debe incorporar una revisión de los supuestos metafísicos-filosóficos de la ciencia moderna que la ha hecho inteligible fundamentalmente como objeto de beneficio mercantil. Puede que seamos testigos, tal como señala Latour, del surgimiento de diversas "naturalezas en disputa". Sin duda que, gracias a los adelantos tecnológicos y productivos, la naturaleza ha sido la fuente de recursos que ha permitido generar un estilo de vida basado en la abundancia. El problema es que dadas las condiciones geo-económicas y políticas, este desarrollo ha sido profundamente desigual. Mientras que en algunas zonas del mundo se goza de una altísima calidad de vida ("calidad" aquí, igual "capacidad de consumo"), en otras como en Chile se persigue ese modo de vivir a costa del más brutal extractivismo; mientras que en otras zonas apenas se "vive". Esta amplitud de paisajes desiguales, también ha producido un modo de pensar, basado en esta diferencia, de entender esta base geo-bio-física que permite nuestra vida como especie desde la alteridad y diversidad de formas del vivir y convivir.

\section{Regímenes de la naturaleza}

La reflexión filosófica acerca del lenguaje comenzó a tomar un lugar cada vez más importante en la filosofía moderna. Desde Nietzsche (1980) hasta Wittgenstein, (1984) pasando por Rorty (1998), la relación hombre-cosa comenzó a tomar relevancia e hizo posible las transformaciones teóricas que dieron expresión al llamado "giro lingǘstico" (Neil 2007). A partir de éste el antiguo nominalismo ha vuelto a

\footnotetext{
${ }^{15}$ Para seguir a Heidegger (2015), concebir al mundo como imagen implica sobre todo la ilusión de un dominio total del mundo. Una ilusión fundamentada en el procedimiento científico, pero que puede estrellarse ante la emergencia de lo catastrófico, de lo gigantesco. En este sentido, Heidegger anticipa la destrucción del mundo (representado en la bomba atómica) por el ejercicio de la razón científica que no ve límites, dado que tiende a una permanente "superación" de este mundo.

${ }^{16}$ Esta crisis de sentido, cuyos primeros signos fueron las críticas postmodernas hoy se profundiza ante la crisis ambiental y ecológica, ante un sistema económico cada vez más devastador. Esta crisis es tanto política, como económica, ecológica como metafísica.
} 
conformar una problemática importante en la relación hombre-lenguaje-mundo, en vista de un creciente anti-esencialismo cada vez más predominante en la teoría contemporánea (Escobar 2009: Laclau \& Mouffe 1987). Este anti-esencialismo emergente sobre todo con la teoría postmoderna y el post estructuralismo de autores como Derrida, Foucault y Deleuze, y permea la discusión que nos atañe sobre el concepto de naturaleza. Es más, es posible sostener que, gracias a este modo de interpretación de la realidad humana, la idea de naturaleza recién puede ser pensada y puesta a discusión, desde una perspectiva política renovada.

Desde el ámbito político-ecológico hasta el científico-tecnológico, la idea de naturaleza parece basarse en distintos modos de comprender y aprehenderla. Esto significa que vivimos una situación de tal complejidad conceptual que resulta difícil sostener un concepto homogéneo de naturaleza que aúne estas diferentes "semióticas" en un concepto "total". Hoy resulta casi imposible "unificar" el concepto de naturaleza, dado que en diferentes ámbitos del conocimiento humano, este ha adquirido una variedad de expresiones que se precisan en campos de saber especializados ${ }^{17}$. A pesar de ello, Arturo Escobar presenta tres maneras diferentes en que la idea de la naturaleza se ha concebido, formas que ha denominado "regímenes de la naturaleza". Estas lecturas se basan en discursos diferenciados, cuya distinción será de utilidad porque nos permitirá esbozar algunas características particulares de cada "régimen", para así conformar y distinguir las comprensiones actuales que existen sobre la naturaleza en diferentes temáticas de estudio e investigación.

1. La "naturaleza capitalista". Es el modo de concebir la naturaleza que hoy se encuentra ampliamente estudiado, por eso sólo mencionaremos algunos tópicos de que conforman esta determinada visión. Desde distintas propuestas tanto filosóficas y sociológicas se pueden considerar las siguientes características del "naturalismo capitalista", como es la naturaleza mercantilizada y desplazada desde el valor de uso al valor de cambio (Marx 1962; Cooper 2008); el carácter instrumental de la ciencia y la tecnología de una naturaleza “domesticada" (Horkheimer 1973; Marcuse 1970); la entrada de lo biológico a la esfera de la actividad económica y la gubernamentalidad (Foucault 2007); estos aspectos reflejan la paulatina

\footnotetext{
${ }^{17}$ Esta profusión de significados también se refleja en la RAE que da 18 significados distintos de "naturaleza", las que comprenden, tanto "orden ya existente en el universo", como "características intrínsecas de las cosas", o la "propensión del orden biológico de los seres naturales", entre muchos otros. Página web de la RAE. (Revisado el 21/10/2016)
} 
maleabilidad a través de los dispositivos biopolíticos, tanto del control de la naturaleza como de la vida humana.

Por otra parte, estudios socio-históricos sostienen que el desarrollo del capitalismo tiene su corolario en la entrada a la modernidad (Weber 2004; Bauman 2005). En este sentido, el desarrollo del capitalismo habría suscitado un cambio de perspectiva epistemológica -la entrada a la modernidad--, lo que concierne a la visión de un mundo de ahí en adelante "convertido en imagen" es decir, un mundo puesto "fuera de sí", exterior al sujeto conocedor, y así dispuesto a la acción y decisión del hombre. Esto atañe sobre todo al vasto desarrollo de la ciencia, cuya comprensión no puede desprenderse a su vez del desarrollo de la técnica moderna ${ }^{18}$ (Arendt 2009; Heidegger 2015).

El desarrollo de la actividad económica capitalista viene acompañado por una serie de transformaciones sociológicas, antropológicas y epistemológicas. Esto significa que el enfrentamiento entre hombre y naturaleza ha sido en los lenguajes del control, la instrumentalización y la planificación. Como señala Escobar, "La naturaleza capitalista es uniforme, legible, administrable, cosechable, fordista." (2009: 289). Esta forma de concebir la naturaleza en la práctica económica, supone una ya no tan radical separación de esta con la esfera humana, ya que implica que esta sea incorporada a nuestra actividad a través de un trabajo de conquista: el hombre se sobrepone a las condiciones naturales, conquistando la naturaleza. De esta manera queda incorporada a la esfera humana, humanizada justamente por medio de la producción económica, vale decir, explotándola. Claramente aquí están presentes todos los elementos míticos y religiosos de la dominación sobre la naturaleza, aunque desprovistos de su carácter de tal ${ }^{19}$. Como señala Leiss en The domination of Nature:

La idea de que el hombre está apartado de la naturaleza y que por derecho propio ejerce un tipo de autoridad sobre el mundo natural, ha sido una característica destacada de la doctrina que ha dominado la conciencia ética de la civilización occidental. (Leis 1974: 32) ${ }^{20}$

\footnotetext{
${ }^{18}$ Respecto a la relación entre la investigación científica y la economía liberal, véase Cooper, (2008) y Goldstein (1987) y Cornejo (2017).

${ }^{19}$ Como señala Raymond Whilliams (1985), la palabra "naturaleza" se revela como uno de las más problemáticas del lenguaje humano, quizás también porque revela tanto nuestra soledad e indistinción como especie, tensionado entre lo animal y lo humano, entre el cambio y lo que permanece o simplemente el no- lugar dentro de la naturaleza que nos depara el hecho terrible de la conciencia humana.

${ }^{20}$ Cita original: "The idea that man stands apart from nature and rightfully exercises a kind of authority over the natural world was thus a prominent feature of the doctrine that has dominated the ethical conscoiusness of western civilization"
} 
En ocasiones se ha descrito al capitalismo como religión (Benjamin 2014) o al menos nacido de un impulso religioso (Weber, 2004), este quizás haya configurado gran parte del imaginario sobre la naturaleza y el proceso de autoridad del ser humano sobre ella. Pero esta visión de enseñoramiento ha mostrado claros signos de crisis generados por el modo de producción y los costos socio-ambientales asociados a éste. ¿Pero de qué es la crisis? ¿Es una crisis de un sistema económico que se enfrenta a cierto límite debido a la escasez de recursos? ¿Es una crisis de una naturaleza "ahí afuera” que ya no puede conllevar (metabolizar) los efectos contaminantes producidos por este sistema de producción? ¿Es una crisis del ser humano que ya no sabe distinguir entre causa y efecto, por lo tanto, entre en cuál de todas las crisis invertir sus energías transformadoras?

Como es sabido, en buena lógica capitalista, los agentes financieros como el FMI y el Banco Mundial sostienen que el desarrollo económico debe llevarse a cabo de forma sustentable y sostenible. Desde el año 1987 la ideología del desarrollo sustentable ${ }^{21}$ configura gran parte de las políticas ambientales de los países de la ONU. Las implicancias que la naturaleza tiene para el discurso del FMI y el Banco Mundial son tanto económicas como políticas, y confluyen a su vez, en una multiplicidad de discursos como el de la pobreza ${ }^{22}$, el cambio climático o de la sustentabilidad. Habrá que interrogar si acaso es el mismo concepto de naturaleza que avala las políticas neoliberales impulsadas por sus principales agentes institucionales. En este sentido, debemos suponer, que ninguna de estas concepciones políticas medioambientales de corte intervencionista $-\mathrm{y}$ a veces conservacionista-, es libre de interés o apolítica y, por tanto, libre de sustraerse a una crítica ideológica (Bourdieu 1985). Es más, como intentamos demostrar

\footnotetext{
${ }^{21}$ Este concepto apareció por primera vez en el informe Brundtland el año 1984. Tal como sostiene Bermejo en su análisis sobre este informe, se ha generado una confusión teórica de este concepto, ya que desde diversas instancias se proponen nuevas lecturas sobre el desarrollo sostenible (DS). Una de las críticas más fuertes señala que el DS es un oxímoron, plagado de contradicciones, ya que se plantea desde la idea del crecimiento ilimitado. Pero en un mundo de recursos finitos esa idea es insostenible. Todos parece indicar que la formulación temprana del DS apuntaba justamente hacia ese punto, pero las reiteradas adaptaciones y reinterpretaciones cargadas de interés político y económico, le han sustraído al DS su potencial crítico.

${ }^{22}$ Una de las últimas publicaciones del Banco Mundial, sostiene la tesis que la pobreza en el mundo puede aumentar a futuro a raíz del cambio climático, ya que las cifras demuestran que los más afectados por desastres naturales son los pobres y sobre todo, los pobres de los países pobres. Así parten del supuesto que el cambio climático puede impactar fuertemente en la pobreza si es que no se toman medidas concretas, es decir, medidas estatales paliativas (políticas públicas), sobre todo asistencia social y nuevas inversiones a modo de acelerar el desarrollo en los países pobres. Así también los estados debieran fomentar un impuesto al carbono para (co)financiar políticas de asistencia social. Lo que queda de esta investigación y sus conclusiones es que se intenta achacar al clima la profundización y aumento de la pobreza humana, una especie de "nuevo naturalismo", con esta ligazón argumentativa entre "pobreza" y "cambio climático": Hay que "proteger" a los pobres, pero haciendo lo que se ha hecho siempre: invertir y fomentar el desarrollo, pero ahora de forma "sustentable". Uno de las conclusiones del estudio dice que al reducir los efectos de cambio climático se estaría así reduciendo el aumento de la pobreza. Esto da la sensación de un "argumento circular", sin saber dónde comienzan la lucha contra la pobreza y la lucha contra el cambio climático (Véase Hallegatte, et all, 2016; También se puede consultar el documento: "Ondas de Choque. Contener los impactos del cambio climático en la pobreza. Nota de Política" 1/3. Banco Mundial).
} 
en este artículo, los diversos usos de un concepto tan polisémico como el de naturaleza implica variados niveles de organización, categorización y visiones específicas sobre la relación hombre-mundo. Algunas de ellas como la que acabamos de enunciar siguen avalando al desarrollo y al crecimiento económico como principales agentes modernizadores, requeridos para la generación de bienestar y calidad de vida, abstrayéndose así de la desigualdad regional y territorial, mantenida, producida e incluso exacerbada por el sistema económico dominante.

2. "La naturaleza orgánica". Esta visión ha ido desarrollándose fundamentalmente a partir de los trabajos en antropología cultural, que, a través de una serie de investigaciones de campo, ha reunido un cúmulo de conocimiento sobre una diversidad de formas de concebir la naturaleza y de cómo nos relacionamos con ella. Según indica Escobar (2007), para la cosmovisión indígena la naturaleza es entendida no como una esfera apartada del "mundo social", sino como parte inexorable de la actividad humana $^{23}$. Esta visión sería propia del mundo indígena "no-moderno" 24 y demuestra que, efectivamente existe una diversidad de maneras de ordenar y categorizar el mundo orgánico, el simbólico o el divino ${ }^{25}$.

${ }^{23}$ Para citar algunos ejemplos de esto, Howell sostiene acerca de los chewongs: "Los chewongs no hacen distinciones categóricas del tipo naturaleza-cultura o mente-cuerpo, pero si diferencias entre nosotros-ellos. La continuidad o la extensión de la humanidad, diría se mueve entrando y saliendo y alrededor de los numerosos seres y objetos nombrados y enumerados de su medio ambiente en los muchos mundos que según ellos existen en la selva." (Howell, 2001: 166) por otra parte Ellen sostiene ante la evidencia etnográfica que las distinciones locales indígenas sobre lo animal, las plantas y los humanos se diferencian de modo fundamental de las categorías occidentales. "La conceptualización de la naturaleza como una colectividad de cosas nunca es tan evidente como en las representaciones generadas por la ciencia occidental y en las generadas por los antropólogos que investigan las clasificaciones folk del mundo natural, donde el punto de referencia explícito o implícito es el paradigma occidental. " (Ellen, 2001: 132)

${ }^{24}$ Aquí resulta pertinente introducir la sospecha que recae sobre la distinción entre el carácter "moderno" de nuestras propias concepciones y el "no moderno" de la cosmovisión indígena: ¿qué tan no-moderno es el indígena hoy? El indígena al aceptar su rol de "protector" de la naturaleza es integrado de esa forma al propio discurso conservacionista occidental, que basa finalmente en la distinción naturaleza-cultura, pero otorgando un estatus de "derecho" a la "madre tierra". ¿De dónde viene esa preocupación por la lucha por el derecho de la tierra, de las aguas...? Esto puede conllevar a una problematización sobre las demandas indígenas en Latinoamérica, la que suscita dos hipótesis: Las demandas indígenas de la "protección del medio ambiente" pueden ser entendidas a) como problemáticas que efectivamente apuntan a una preocupación de grupo por la conservación de su cultura ligada a una concepción de territorio o b) como problemáticas instaladas por las políticas gubernamentales de organismos estatales o del trabajo de ong`s. Como dice el Principio 22 de la Declaración de Rio: "Los pueblos indígenas y sus comunidades, así como otras comunidades locales, desempeñan un papel fundamental en la ordenación del medio ambiente y en el desarrollo debido a sus conocimientos y prácticas tradicionales."

Creemos que no podemos negarle el carácter de "moderno" al indígena. Sustraerle esa característica es restarlo de la historia, colocarlo nuevamente como sujeto "sin historia", obligarlo a permanecer en los confines de la naturaleza (lo que se adecuaría a su rol de protector de ésta). Para un detallado y a la vez sucinto análisis de esta temática véase Zapata (2016). Sin duda es interesante también, el reconocimiento de "los derechos de la naturaleza" del estado boliviano. Un hecho sin precedentes, quizás insuficientemente analizado, que un estado reconozca derechos a una naturaleza no- humana. Este hecho, sin duda, proyecta un halo de profunda incertidumbre en el corazón de la teoría política y filosofía política occidental, porque la aplicación del derecho ya no constituiría únicamente un privilegio humano.

${ }^{25}$ Ante esto es pertinente aquí referirme a la distinción que hace Descola de los diferentes modos de identificación y relación con la naturaleza. El antropólogo francés distingue entre el animismo, el totemismo y finalmente el naturalismo moderno, para 
A diferencia de nuestras sociedades caracterizadas por el funcionamiento de diferentes sistemas autónomos (arte, política, religión, economía, etc.) la "sociedad indígena", aunque ya configurada por las relaciones con el "hombre blanco", mantiene relativa autonomía respecto a la cultura dominante ${ }^{26}$. En ella, los sistemas que configuran sus conocimientos, parentesco, mitología, formas de producir o ritualidades, según la experiencia etnográfica, "no se viven” de forma tan diferenciada como en nuestras sociedades, lo que significa que en la vida indígena no se expresan las diferenciaciones basales tan pronunciadas como en nuestra cultura. Por eso, se puede entender que la configuración naturaleza y cultura, ha sido a veces discutido, pero en ocasiones tomado como un hecho poco discutido en la literatura antropológica hasta hace algunas décadas.

3. La antropología social y cultural tiene mucho que aportar a la discusión sobre la relación naturaleza-cultura, porque los múltiples datos empíricos recogidos por los etnólogos arrojan una variedad de órdenes taxonómicos, formas de clasificación y representación que no operan bajo la misma lógica de separación entre naturaleza y cultura. El antropólogo norteamericano Tim Ingold (2000), sostiene que el desarrollo de la antropología cultural comúnmente contradice una visión establecida en las ciencias de la naturaleza, a saber, un punto de vista divergente en lo que respecta la relación del observador y el mundo que le rodea: por un lado, la ya mencionada separación entre la humanidad y la naturaleza, y por otro, la de la tradición (no moderna) y la cultura occidental (moderna). Sin duda gran parte de nuestra tradición de pensamiento moderno está basada en este tipo de dicotomías. Así también habrá que entender el desarrollo histórico de la antropología cultural heredera de los fundamentos epistemológicos y ontológicos del pensamiento moderno, pero a la vez, posibilitada de reflexionar no solo sobre sus prácticas etnocéntricas, sino también sobre su constitución como práctica científica, escritural y narrativa. Ello le ha posibilitado a la antropología una no corta trayectoria de auto-reflexión (Geertz 2000; Reynoso 2003). Su amplitud respecto al campo de conocimiento humano la ha convertido en una especie de "visión de visiones" que integra el vasto universo de diferentes culturas humanas (Ingold 2000: 15). Sin embargo, también es importante constatar que en la historia del pensamiento antropológico han existido esfuerzos

\footnotetext{
caracterizar distintos modos de clasificación y taxonimización del mundo de los humanos y no humanos. (Descola, 2001) Al respecto véase también la tipología propuesta por Gísli Palson de diferenciar orientalismo, paternalismo y comunialismo como diferentes modos actitudinales, lo que concierne una episteme y una praxis específicas de tratar a la naturaleza.

${ }^{26}$ Más bien se podría hablar de lucha por la "autonomía" lo que a veces se traduce en resistencia o lucha directa de los pueblos indígenas por su territorio. Esto es un tema privilegiado en la etnografía, donde se tiende, nuevamente, a oponer el mundo de la vida moderna, basado en el desarrollo y el crecimiento económico, y la vida indígena, entendida como "no- moderna", que configura un estilo de vida radicalmente distinto.
} 
por superar esta estructura dualista naturaleza-cultura, antaño aceptada como verdad "obvia", la cual hoy es parte de una de las preocupaciones de la antropología enfocada a entender cómo el indígena construye sus percepciones y representaciones, no de una realidad externa (naturaleza), sino de un determinado "modo de ser" (Ibáñez 2001) que efectivamente no concibe esta separación, ni en la teoría, y menos en la práctica ${ }^{27}$.

4. "La tecnonaturaleza". Ella es quizás la prueba más palpable de la "colonización de la naturaleza" por parte de la acción humana, mediante la tecnología. Esa es al menos la visión de numerosos investigadores que han reflexionado sobre el impacto de la tecnología en la vida vegetal, animal y humana (Jonas 1984; Habermas 2002; Sloterdijk 2000). Quizás las técnicas de ADN recombinante, la clonación y las nano-tecnologías son sólo algunos de los signos más visibles que evidencian que los procesos biológicos y genéticos se tornan cada vez más invasivos de un núcleo "natural" que se consideraba inviolable. Es por eso que las tendencias de los teóricos es tender hacia la tecno filia o la tecno fobia (Escobar, 2009). La tecnonaturaleza hace posible la serie de combinaciones de lo artificial, lo informático y lo orgánico, con lo cual la naturaleza en sus aspectos orgánicos, va quedando obsoleta (Sibilia, 2009). Como sostiene la teórica feminista Donna Haraway:

Las máquinas de este fin de siglo han convertido en algo ambiguo la diferencia entre lo natural y lo artificial, entre el cuerpo y la mente, entre el desarrollo personal y el planeado desde el exterior y otras muchas distinciones que solían aplicarse a los organismos y a las máquinas. (Haraway, 1991: 258).

Así mismo, un amplio desarrollo de los estudios de Ciencia y Tecnología ha permitido elaborar otros referentes teóricos que paulatinamente comienzan a ser incorporados al lenguaje de las ciencias sociales y la filosofía ${ }^{28}$. Lo interesante es que estos esfuerzos por tematizar la naturaleza "hibridizada" se tornan

\footnotetext{
${ }^{27}$ Esta distinción basa sus argumentos en la crítica que propone el sociólogo de la ciencia, Bruno Latour en su ya célebre ensayo Nunca fuimos modernos (2007), en el cual sostiene que la modernidad ha producido un "autoengaño generalizado" al entender al ser humano separado de la naturaleza a su vez que parte del mundo cultural. Autoengaño porque, así sostiene el autor, en las prácticas culturales y sobre todo en la práctica científica mezclamos continuamente naturaleza y cultura, sujeto y objeto. Lo que la teoría de la modernidad intenta mantener en ámbitos separados, la práctica científica constantemente junta en un híbrido de naturaleza y cultura.

${ }^{28}$ Ya existen determinados esfuerzos teóricos que proponen más bien "obviar" que "resolver" la "aporía dualista". Tal es el caso de los cuasi-objetos y cuasi- sujetos de Michel Serres, la teoría del actor-red y los híbridos de naturaleza y cultura de Bruno Latour, los sistemas experimentales y objetos epistémicos de Hans Joseph Rheinberger, entre otros conceptos, que se sitúan en un espacio intermedio entre la naturaleza y la cultura. Vivimos hoy una realidad tan compleja y llena de combinaciones
} 
realidades cada vez más palpables, que en ocasiones fuerzan nuestras categorías de pensamiento en virtud de las mezclas, combinaciones y mixturas entre tecnología, información y naturaleza ${ }^{29}$.

En esto reside la relevancia de la reinvención de la naturaleza, como también en el potencial de la tecnonaturaleza para crear una alteridad biológica radical. Si la naturaleza capitalista introdujo a la naturaleza en el dominio de lo Mismo, y la naturaleza orgánica era/es compuesta siempre de formas localizadas, la tecnonaturaleza hace que la alteridad prolifere. (Escobar, 2009: 303).

Mientras que los tipos de naturaleza antes enunciadas refieren justamente a formas más o menos localizadas, sean de producción a pequeña escala como en el caso de las poblaciones indígenas o grandes cadenas extractivas de la economía mundial, esta localización comienza a perderse en los confines a veces confusos de una tecnología cada vez más autónoma. La realidad de las nuevas tecnologías de la información, las biotecnologías y la Inteligencia Artificial ya está provocando una crisis profunda de este paradigma ontológico descrito en este articulo, porque continuamente comienzan a tomar forma nuevas alteridades e identidades híbridas (Haraway 1991; Rose 2007; Latour 2007; Latour 2010; Guattari 2015).

Pero la pregunta que paulatinamente adquiere mayor relevancia, es cómo la tecnonaturaleza adquiere expresión en el periodo del actual capitalismo. ¿Acaso la entrada a un mundo "pos-natural" corresponde a la inminente desaparición de la "naturaleza orgánica"? ¿Acaso lo que una vez existía en estado naturalorgánico, tenderá a ceder paulatinamente a los imperativos de la recombinación, la virtualidad y el diseño dentro del contexto de esta nueva era biocapitalista? (Sunder Rajan 2006; Cooper 2008; Sibilia 2009). Entonces, ¿cuál es la relación entre tecno-naturaleza y naturaleza capitalista? ¿Acaso la primera no es sino expresión de un desarrollo monstruoso e incontrolado de la segunda?

\footnotetext{
entre sistemas semióticos, inteligencia artificial, desastres ecológicos, y prácticas humanas, que estos enfoques, al parecer, comienzan a tener cada vez más sentido, y ser populares, sobre todo en la ecología política y la STS.

${ }^{29}$ Donna Haraway en su Manifiesto Cyborg sostiene: "La naturaleza y la cultura son remodeladas y la primera ya no puede ser un recurso dispuesto a ser apropiado e incorporado por la segunda". (Haraway, 1991: 256) A sí mismo consciente del problema del dualismo ontológico, el ecologista mexicano Enrique Leff sostiene: "El problema no se plantea ya en términos de separaciones absolutas entre estos pares de órdenes opuestos (Lo real y lo simbólico). Estos cada vez se vuelven más plásticos, el razonamiento que buscaba justificar su perfecta separación o su ideal unificación cede ante la presencia de "entes híbridos" y la construcción de nuevos esquemas de un pensamiento complejo en los que se plantean las interrelaciones e interacciones entre lo material y lo simbólico". (Leff, 2004: 71-72).
} 
Resulta interesante constatar que estas problematizaciones generan acercamientos entre diversas áreas de estudio, sobre todo las denominadas Science Studies ${ }^{30}$ o STS, que desde autores diversos han interrogado el dualismo ontológico naturaleza-cultura, supuesto base del pensamiento científico moderno. Sin duda un desarrollo teórico que suscitó y aún provoca fuertes reacciones sobre todo en aquellos filósofos que tratan defender cierta pureza epistemológica de la ciencia (Bunge 2005; Bunge 2006).

Estas tres formas de concebir la naturaleza probablemente no serán las únicas, pero como aproximación analítica contribuye a dilucidar y poner en juego los diferentes conocimientos acerca de esta temática, sobre todo en vista a los veloces procesos de transformación tecnológico que involucran cada vez a más actores. Ciertamente la cultura humana en su vasto universo de diferencias no ha quedado al margen de esta problematización, ya no es únicamente el "ciudadano moderno", citadino, que se ve directamente interpelado por este tipo de transformaciones ${ }^{31}$, sino también el mundo campesino e indígena comienza a verse cada vez más afectado por esta problemática (Zapata 2016). Esta extensión del campo de poder de la ciencia tecnificada en su coalición con la gran industria, ha provocado también la entrada de diversos actores a un mundo en disputa: activistas políticos y ecológicos, científicos, transnacionales de farmacéutica, bioprospectores, ONG's ecológicas, los estados nacionales, entre otros, han conformado un amplio espectro de discusión sobre lo que Leff (2004) denominó la "apropiación social de la naturaleza".

Sin duda que la pregunta central sobre la naturaleza aún sigue siendo nebulosa, llena de interrogantes que no se pueden situar en lugares bien diferenciados, sean estos en asuntos de política, ciencia, epistemología, ecología o cultura, sino más bien constituyen una red de diferentes discursos que liga todos estos elementos, haciéndolos más densos y complejos, obligándonos a ir despacio en el proceso del entendimiento, para no perdernos en las marañas de la selva teórica.

\footnotetext{
${ }^{30}$ Véase para esta discusión las obras de los sociólogos de la ciencia Bruno Latour (2007) (2001), Karen-Knorr Cetina (2002), Hans-Georg Rheinberger (2006), Bloor (2003) entre otros. Así como también de la filósofa de la ciencia Isabel Stengers (1997; 2008) y Donna Haraway (1991).

${ }^{31}$ El argumento se sostiene a partir del concepto de Nikolas Rose "biological citizenship", este se refiere al empoderamiento de la ciudadanía acerca de temas científicos y médicos. Claramente internet hoy es una herramienta que nos permite informarnos e incluso entender el lenguaje del especialista. La noción de "ciudadano biológico" da cuenta de una situación paradójica porque sitúa en un campo de tensión la información que circula en internet, las redes o blogs que promueven y divulgan conocimiento experto, el saber del experto propiamente tal y el incremento de las facultades de decisión de la población civil no-experta.
} 


\section{Entramados sociopolíticos de la naturaleza}

En este contexto de complejidad, la comprensión de la "naturaleza" podría encaminarse a partir de un modo de funcionamiento que despliega su carácter semiótico en distintos niveles de saberes y prácticas humanas. Tiene, pues, un carácter rizomático ${ }^{32}$ (Deleuze y Guattari 2014), ya que conecta necesariamente con una serie de teorías, discursos y prácticas, pero sin un orden necesario o un centro unificador que estratifique en importancia algún elemento sobre otro. Atender a esta perspectiva contribuiría, quizás, a una mejor comprensión acerca de la naturaleza en su complejidad, cargada de significados diversos según los discursos políticos, económicos o científicos que lo involucran y lo ponen en juego. En este sentido entendemos que el problema de la "naturaleza" responde, en efecto, a un entramado sociopolítico toda vez que contemplamos que tal problema se encuentra atravesado por fuerzas políticas que se materializan en prácticas económicas, científicas, y sociales.

A continuación, propondremos dos cruces temáticos en los cuales se expresa la compleja problematización de la naturaleza, a través de una diversidad de conexiones entre instancias tecnológicas, políticas y económicas.

1. El dispositivo Biotecnológico. La biotecnología en E.E.U.U. encontró un importante margen de desarrollo a partir de la era del presidente Reagan, y ha significado la cada vez más compleja relación entre la industria, ciencia y tecnología. A partir de los años '90 emergieron la serie de posibilidades atribuidas al avance biotecnológico y con ello la posibilidad no solo de manipular técnicamente los procesos orgánicos animales y vegetales, sino también un importantísimo nuevo campo de inversión y financiamiento en espera de posibles ganancias futuras. Los nuevos mercados fueron paulatinamente generados, sean desde la investigación y posterior producción basado en ingeniería genética, muchas veces obtenidos mediante formas legalizadas de bioprospección, así como la permanente exposición "informática" de la población a los nuevos avances en genética y biología molecular. Para atender a esta compleja red urdida entre tecnología y política, se debe tener presente esta relación entre industria, ciencia y las instancias económicas que promueven la búsqueda de nuevos mercados, campos de explotación y

\footnotetext{
${ }^{32}$ El rizoma es todo un programa metodológico que intenta desprenderse de la lógica del significante tan presente en el psicoanálisis, como en la lingüística desde Saussure. Una de las características del rizoma es su conectividad "sin orden" de diversos elementos heterogéneos. Otra de sus características es su multiplicidad en función de sus diversas conexiones. En resumen, la lectura rizomática de la naturaleza es la puesta en movimiento de una serie descentrada de elementos políticos, ecológicos, económicos, pero sin un eje ordenador que jerarquiza.
} 
producción (Cornejo 2017; Smith 2007). Así también, con el descubrimiento del “oro verde”, los genes fueron "liberados" de su restricción legal, dando paso así no sólo a la posibilidad de su manipulación, sino también a su directa apropiación por medio de políticas de derecho de propiedad intelectual (Rifkin 1999; Mies 2002). Junto con ello se posibilitó todo un programa de investigación impulsadas por la industria farmacéutica y biotecnológica. Ante los desarrollo antes descritos, creemos que toda esta red de fenómenos tiene incidencia en la propia definición sobre la naturaleza que hoy vivimos, ya que, como sostuvimos más arriba, configuran permanentemente nuestra relación con ella, ya no como algo "exterior", sino como "ente" manipulable desde sus procesos genéticos, así como también, apropiable en términos de capitalización $\mathrm{n}^{33}$.

La naturaleza, concebida desde el discurso tecno-científico se expresa en el programa de la biotecnología y la ingeniería genética como campos de aplicación e intervención en la biología de los sistemas vivientes (Cooper, 2008). La biología que antaño estudiaba los cuerpos como un conjunto de funciones “mecánicas", hoy ya está posibilitado de diseñar estos cuerpos en función de ciertos caracteres deseados. Esto significa, por un lado, la entrada en la obsolescencia del cuerpo biológico (Sibilia, 2009) y, por otro lado, a una sociedad regida por una eugenesia liberal-consumista (Habermas, 2002). Esto trae consigo la paulatina transformación y redefinición de los conceptos que sostienen "lo natural" como un campo separado de la actividad humana. En este sentido, la creciente artificialidad que supone un control cada vez más vasto sobre los procesos orgánicos, supone un proceso de creciente hibridación. "Lo orgánico" y "lo natural" comienzan a fundirse en las conceptualizaciones del lenguaje tecnificado de las ciencias de la vida. Pero la tendencia a concebir estos procesos de forma "tecnofílica" o "tecnofóbica", da cuenta de la compleja transformación del sentido del concepto de naturaleza, que a su vez involucra nuestra comprensión del ser humano como ente social y natural a la vez. Discursivamente seguimos en la ilusión que estos órdenes no se tocaban, ya que la separación la creíamos obvia y evidente. Pero los "teóricos de la hibridación" como Donna Haraway o Felix Guatarri han reconocido en esta transformación un posible

\footnotetext{
${ }^{33}$ La teórica ecofeminista Vandana Shiva, refiriéndose al impacto que los sistemas de Derecho de Propiedad Intelectual (DPI), a partir de la otorgación de patentes a organismos vivos, sus plasmas germinales, genes, tienen sobre las comunidades locales y tradicionales, dice: "El concepto eurocéntrico de propiedad sólo considera inversión la inversión de capital y, por consiguiente, cree que los rendimientos de la inversión de capital es el único derecho que necesita protección. Las comunidades y las culturas indígenas no occidentales saben que la inversión también puede ser de trabajo o de atención y cuidados (...) el cercado empresarial se está produciendo de dos maneras. En primer lugar, los sistemas de DPI permiten el cercado de biodiversidad y conocimientos; de esta manera se produce un debilitamiento de las tierras comunales y de la comunidad. En segundo lugar, se está tratando a la empresa como si fuera la única forma de asociación con personalidad jurídica." (Shiva, 2003: p. 46-47).
} 
campo de emancipación a partir de la emergencia de nuevas identidades y alteridades basadas en lo híbrido. La tecno-naturaleza, concebida por Escobar (2009), se perfila en estos cruces entre humanidad y tecnología, ciencias de la vida y nuevas formas de control biopolítico no solo de la "naturaleza humana", sino de la naturaleza misma. Está por verse cuántos de estos procedimientos finalmente pueden desembocar en nuevas formas biopolíticas emancipatorias que tomen por objeto no solo la vida humana, ya por si inmersa en estos mecanismos de planificación y control, sino que también tomen por objeto la re-significación de la naturaleza, como concepto "singular" (una naturaleza, o varias naturalezas), inmersa en los procesos de transformación acerados por la técnica y la ciencia.

2. La dimensión económica sobre la naturaleza. En relación a los dispositivos económicos, el discurso de la ONU a través del Consejo Económico y Social de las Naciones Unidas (ECOSOC), promueve la protección del medio ambiente frente a los intereses del capital nacional e internacional. Pero estas instancias de protección a su vez, son promovidos por el mismo FMI y el Banco Mundial, principales entes financieros de la ONU y así, del ECOSOC ${ }^{34}$. Esto nos lleva irremediablemente a la sospecha que la concepción indígena de la protección del medio ambiente ${ }^{35}$ se encuentra en ocasiones atravesada, por no decir, "cooptada", por las promociones políticas del ECOSOC. Esto a su vez genera una comprensión ambigua e imprecisa sobre la naturaleza, ya que tanto los pueblos indígenas como las instancias de promoción de políticas neoliberales poseen distintas "visiones" sobre ella, pero que en este eje de relaciones no parecen contradecirse: ambas se fundan, discursivamente, en la "protección del medio ambiente" y el "desarrollo sostenible"; el problema reside en que el desarrollo sostenible practicado durante años por las culturas tradicionales e indígenas no es el mismo que pregona los principales agentes promotores de políticas neoliberales ${ }^{36}$. Sobre todo en Latinoamérica, durante la última década han surgido diferentes puntos de vista, amparados en el modo de vida de los pueblos indígena que buscan responder a

\footnotetext{
${ }^{34}$ Véase organigrama de la ONU. En este el BM y FMI aparecen como agentes "externos" pero como principales entes que financian las políticas propuestas por las Naciones Unidas. Disponible en: http://www.un.org/es/aboutun/structure/pdf/unchart_11x17_sp_color.pdf (Revisado 23/10/2016)

35 Tanto algunos estudios antropológicos, como las teorizaciones de la ecología política, sostienen que la producción indígena se lleva a cabo de forma sustentable, respetando los ciclos de renovación de la naturaleza.

${ }^{36}$ Es interesante constatar al respecto que gran parte de las demandas indígenas se refieren al derecho de apropiación de la naturaleza, sea en forma de agua, tierra u otros recursos naturales. Esto en gran parte es promovido por ONG`s medioambientales y antropólogos comprometidos con las demandas indígenas. Véase al respecto los trabajos del antropólogo colombiano Arturo Escobar (2000; 2010; 2014). Así como también la discusión sobre uso de la propiedad común que ya comienza a perfilarse como tema de investigación en algunos autores (Hardin, 1968; Ostrom, 2000; Secreto, 2011; Laval \& Dardot, 2015) Esto involucra además la discusión sobre la propiedad de los "objetos de conocimiento", como el uso de internet como plataforma universal y libre. (Hess \& Ostrom, 2016).
} 
las políticas extractivistas del modelo económico hegemónico y a la capitalización de la naturaleza ${ }^{37}$. En este sentido, la discusión sobre los extractivismos en Latinoamérica no sólo involucra elementos estrictamente económicos, sino sobre todo elementos culturales que dan forma a vías alternativas de vivir y convivir con el medio ambiente. En este contexto, desde Latinoamérica se intenta construir un discurso político basado en la diferencia y gran riqueza cultural de la región, que busca emanciparse de un discurso totalizador euro y americano centrista, no sólo desde el punto de vista económico sino también epistemológico y cultural (Santos 2013). Ante esto, el conocimiento indígena, aunque cada vez más mercantilizado en sus distintos aspectos ${ }^{38}$, se puede convertir en poderoso ejemplo de convivencia que subvierte las tradicionales concepciones de naturaleza.

\section{¿Naturaleza: ¿Un problema valórico? La naturaleza como valor}

Vivimos una época histórica donde el desarrollo de la teoría sociológica, antropológica y filosófica de a poco vuelca sus problemas hacia un campo de estudio que busca re-hacer la comprensión sobre la relación del hombre con su medio ambiente, desde una concepción cada vez más anti esencialista (Escobar 2009). Este desarrollo teórico converge, a su vez, con la creciente preocupación ecológica y con ello la necesidad de redefinir lo que entendemos por naturaleza.

Desde el comienzo de la modernidad que el ethos científico está atravesado por esta misma preocupación: la creación de un conocimiento certero del funcionamiento de las leyes naturales. Pero el desarrollo de la tecno-ciencia y la biotecnología ha profundizado aún más este "proceder anticipador" (Heidegger, 2015), en virtud de un control cada vez más acucioso de los cuerpos, de los organismos, de los territorios, y su funcionamiento. Pero ya desde algunos años que los sociólogos sostienen que la ciencia no opera sobre los procesos naturales, y que más bien los produce y los construye, de acuerdo a ciertas coordenadas que son a la vez metodológicas e históricamente contingentes (Knorr-Cetina 2002; Bloor 2003; Rheinberger 2006). Este nuevo enfoque comenzó a comprender el proceso científico como un espacio donde naturaleza

\footnotetext{
${ }^{37}$ Dentro de este contexto el concepto de "buen vivir" desarrollado en países como Bolivia y Ecuador ha aportado "...a la emergencia de una gramática común que ilustra el cruce innovador entre la matriz indigeno-comunitaria, defensa del territorio y discurso ambientalista. En esta línea, el giro eco-territorial no es exclusivo de los países con fuerte presencia de los pueblos originarios, sino que abarca gran parte de América Latina, donde se han venido multiplicando las resistencias campesinoindigenas y los movimientos socioterritoriales y ambientales (...) Así las luchas eco-territoriales apuntan a las expansión de las fronteras del derecho, al tiempo que expresan una disputa social alrededor lo que se entiende o debe entenderse por "verdadero desarrollo" o "desarrollo alternativo". (Svampa, 2016: 191).

${ }^{38}$ No sólo desde el punto de vista eco y etnoturístico, sino además como sucede en Perú con el caso de Ayahuasca y la industria turística que busca explotar la "sed de nuevas experiencias" de turistas venidos de diferentes partes del mundo. Véase el artículo de Le monde diplomatique, "Fiebre Chamánica en Amazonía" de Jean-Loup Amselle. Enero-febrero 2014.
} 
y cultura entran en una relación de inmanencia, en la cual resulta cada vez más complejo distinguir los procesos naturales de los procesos culturales o sociales, ya que ambos se constituyen mutuamente. Al menos es la mirada con la cual los estudios de ciencia y tecnología u otras metodologías, como la teoría del actor Red, comienzan a concebir un mundo cada vez más denso provisto de agentes humanos y nohumanos que a su vez requieren de nuevas interpretaciones, conceptos y lenguajes para descifrar este haz de relaciones (Latour, 2004).

Por otro lado, el llamado "proteccionismo" al cual es sometida la naturaleza de acuerdo al discurso del ECOSOC, aún pregona la idea de una naturaleza que debe ser preservada y cuidada para no ser "contaminada" por la acción productiva-destructiva del ser humano. Estos discursos parecen contradecir al programa tecnocientífico, tal como hemos indicado. Por un lado, aquel que aboga por su apropiación y dominio a través de la manipulación técnica y los sistemas de derechos de propiedad intelectual (Shiva 2003), y otro por el proteccionismo de una naturaleza depositada “ahí fuera". Pero esta contradicción merece ser tomada en cuenta a la hora de interrogar las principales instituciones que sostienen los discursos de conservación en consonancia con la teoría del desarrollo sostenible. Pero ¿en un gesto axiológico, a qué cosa le daremos más importancia, al crecimiento económico o la protección de la naturaleza? ${ }^{39}$ Aunque en vista a las políticas de conservación ambas "vías" -protección a la vez que crecimiento- no parecen contradecirse, aun así, lo que queda es un problema que atañe a nuestras valoraciones, y el sentido de dar valor a las cosas. Porque en términos precisos, la teoría del desarrollo sostenible defiende la idea de un crecimiento a partir de la protección del medio ambiente, que, desde la lectura neoliberal, implica a la vez la creciente capitalización de la naturaleza a través de su conservación como áreas de diversidad biológica, humedales y ecoturismo (Smith, 2007), siempre en clave mercantil. Lo que es innegable es que, ante la ideología del crecimiento económico, defendido aún en múltiples lugares del pensamiento económico, se sigue impulsando la búsqueda de nuevos mercados y nuevas fuentes de explotación, involucrando a la naturaleza con nuevos modos de producción y creación de riqueza. Es este modo de proceder-ideológicamente motivado-el que nos ha llevado a la situación en la cual hoy nos encontramos.

\footnotetext{
${ }^{39}$ Esta pregunta queda bien expresada y encuentra una interesante expresión en el caso del proyecto de la Minera Dominga, que ha sido rechazado por el gobierno actual de Michel Bachelet, pero que ha sido tema de debate y discusión, ya que diferentes organismos estatales sostienen visiones dispares sobre el posible impacto ambiental de este proyecto en la zona de Coquimbo y La Serena. A tal punto ha sido la virulencia de este tema que significó el quiebre dentro del propio gobierno. Las presiones políticas sobre la economía nacional afecta de sobremanera esta discusión, donde parece primar la consigna: "trabajo para todos y pujante economía", sobre la idea del "cuidado y resguardo de la diversidad biológica de la flora y fauna nativa". Nuevamente el problema parece ser axiológico, respecto a la dificultad real de consolidar protección ambiental y desarrollo económico.
} 
Cuando en la teoría contemporánea comienzan a surgir voces que señalan que la naturaleza "no existe" o que habrá que abandonar la pretensión moderna de los límites entre ésta y la cultura humana, no sólo estamos en presencia de síntomas sino de una profunda crisis de sentido. Además de la pregunta de por sí compleja de la sostenibilidad de la base material y orgánica que posibilite, a la larga, la supervivencia de la especie humana, sin caer en la lucha total por los recursos naturales debido a su escasez y la profundización de la brecha "norte-sur" en cuanto al goce de una vida de consumo y calidad de vida.

Es en este contexto y tomando en cuenta la creciente transdisciplinariedad teórica que se requiere para comprender este fenómeno, sostenemos que la idea de naturaleza ha sido transformada durante la última etapa del capitalismo avanzado, a raíz de diversas instancias (políticas, económicas, ecológicas, científicas) que no sólo involucran diferentes modos de concebir la naturaleza, sino que también obligan repensar nuestras conceptualizaciones en virtud de afinar nuestra comprensión acerca de ella, a la vez de "nuestra" cultura. Esto sin duda involucra y pone en juego nuestra capacidad de renovar nuestras categorías de pensamiento y acción, todavía más en un escenario móvil y flexible como el de nuestra actualidad. En este sentido, es necesario orientar la investigación hacia otro tipo de comprensión sobre la naturaleza, ya no "objetivada" científicamente para ser comprendida "desde adentro hacia afuera" desde la seguridad de la cultura que alberga, hasta las leyes impersonales que rigen la naturaleza (Darwin). El kantismo parece estar siempre presente en estas afirmaciones, dando cuenta de esta aporía anclada en nuestra tradición de pensamiento: Naturaleza "en sí" incognoscible vs. diversas representaciones de naturaleza (conocimiento relativo, humano (Latour 2007; 2010; Descola 2013) Sin duda estamos ante una aporía, quizás imposible de resolver si es que no se revisan también los conceptos "anclados" en ella: cultura indígena, historia humana, naturaleza humana. Al menos podemos comenzar a interrogar las categorías y definiciones que hacemos de naturaleza en función de repensar completamente nuestra propia condición humana y futura vida en este planeta.

\section{Referencias bibliográficas}

Arendt Hannah (2009), La condición humana. Buenos Aires: Paidós.

Amselle Jean-Loup (2014), “Fiebre chamánica en Amazonía”. Le monde diplomatique.

Baudrillard Jean (2000), Las estrategias Fatales. Barcelona: Anagrama.

Baumann Zygmunt (2005), Legisladores e intérpretes. Buenos Aires: Universidad Nacional de Quilmes. 
Benjamin Walter (2014), El Capitalismo como religión seguido de Fragmento teológico-político. Madrid: La Llama.

Bermejo Gómez de Segura Roberto (2014), Del Desarrollo sostenible según Brundtland a la sostenibilidad como biomimesis. UPV/EHU.

Bloor David (2003), Conocimiento e imaginario social. Barcelona: Gedisa.

Bourdieu Pierre (1985), ¿Qué significa hablar? Economía de los intercambios lingüísticos. Madrid: Akal.

Brundtland Gro Harlem et all. (1987), Nuestro futuro común. Informe de la comisión mundial sobre el medio ambiente y el desarrollo. ONU.

Bunge Mario (2005), La ciencia. Su método y su filosofía. Buenos Aires: Editorial sudamericana. (2006) A la caza de la realidad. La controversia sobre le realismo. Barcelona: Gedisa.

Castro Tejerina Jorge (2008), "Epilogo: Antropotecnias desbocadas. A caballo entre Hans el Listo y el pequeño Hans". En Tomás Sánchez Criado (edit.): Technogénesis. La construcción técnica de las ecologías humanas. Vol. 2. Madrid: AIBR.

Cooper Melinda (2008), Life as Surplus. Biotechnology and capitalism in the neoliberal era. Washington: University of Washington Press.

Cornejo Sascha (2017), Políticas de la especie. Eugenesia, vida e ingeniería genética. Santiago de Chile: RIL.

Deleuze Gilles y Felix Guatarri, (2014) El anti Edipo. Capitalismo y esquizofrenia. Barcelona: Paidós,

Deleuze Giles (2005), La lógica del sentido. Barcelona: Paidós.

Derrida Jaques, (2000), De la gramatología. México D. F.: Siglo XXI.

Descola Phillipe (2013), Jenseits von Natur und Kultur. Berlin: Suhrkamp

(2014), Die Ökologie der Anderen. Berlin: Matthes \& Seitz.

Descola Phillipe y Gísli Pálson (Edit.) (2001), Naturaleza y sociedad. Perspectivas antropológicas. México D.F.: Siglo XXI.

Duran Francisco (2001), El Antropoceno. La crisis ecológica se hace mundial. Barcelona: Virus,

Escobar Arturo (2009), El final del salvaje. Naturaleza, cultura y política en la antropología. contemporánea. Santa Fé de Bogotá: Cerec. 
(2010) Una minga para el postdesarrollo: Lugar, medio ambiente y movimientos sociales en las transformaciones globales. Lima: Universidad Nacional Mayor de San Marcos. Fondo Editorial de la Facultad de Ciencias Sociales.

(2014) Sentir pensar con la tierra. Nuevas lecturas sobre desarrollo, territorio y diferencia. Medellín: Ediciones UNAULA.

(2000) "El lugar de la naturaleza y la naturaleza del lugar: ¿globalización o postdesarrollo?" En Edgardo Lander (comp.): La colonialidad del saber: eurocentrismo y ciencias sociales. Perspectivas Latinoamericanas. Buenos Aires: CLACSO, Consejo Latinoamericano de Ciencias Sociales.

Foucault Michel (2012), Historia de la sexualidad. Tomo I. La voluntad de saber. Buenos Aires: Siglo XXI.

(2007), Nacimiento de la biopolítica. Buenos Aires: F.C.E.

Aires: Siglo XXI.

(2003), Las palabras y las cosas. Una arqueología de las ciencias humanas. Buenos

Freud Sigmund (2010), Das Unbehagen in der Kultur und warum Krieg? Wiesbaden: Marix.

Geertz Clifford (2000), La interpretación de las culturas. Barcelona: Gedisa.

Gergen Kenneth J (2006), El Yo saturado. Dilemas de identidad en el mundo contemporáneo. Barcelona: Paidós.

Guattari Felix (2005), ¿Qué es la ecosofía? Textos presentados y agenciados por Stephane Nadaud. Buenos Aires: Cactus.

Habermas Jürgen (2002), El futuro de la naturaleza humana. ¿Hacia una eugenesia liberal? Barcelona: Paidós.

Hallegatte Stephane et all. (2016), Shock Waves: Managing the Impacts of Climate Change on Poverty.. Climate Change and, Development Series. Washington, DC: WorldBank. doi:10.1596/978-1-4648-06735. License: Creative Commons Attribution CC BY 3.0IG

Haraway Dona J. (1995), Ciencia, cyborgs y mujeres. La reinvención de la naturaleza. Madrid: Cátedra.

Hardin Garret (1968), The tragedy of the commons. Science, New Science. Vol. 162. N 3859. 12431248.Heidegger, Martin. (2015) Holzwege. Frankfurt am Main. Klosterman.

Heidegge, M. (2007), Filosofía, ciencia y técnica. Santiago de Chile: Editorial Universitaria. 
Heidegger M. (2002), Ser y tiempo. Santiago de Chile: Editorial Universitaria.

Hess, Charlotte \& Ostrom, Elinor (eds) (2016), Los bienes comunes del conocimiento. Madrid/Quito: AIEN/Traficantes de sueños.

Hobbes Thomas (2009), Leviathan. O la materia, forma y poder de un república eclesiástica y civil. Buenos Aires: F.C.E.

Horkheimer Max (1973), Crítica a la razón instrumental. Buenos Aires: Sur.

Ibañez Tomás (2001), Municiones para disidentes. Realidad-verdad-política. Barcelona: Gedisa.

Ingold Tim (2000), The perception of the environment. Essays of livelihood, dwelling and skill. London: Routledge.

Jonas Hans (1984), Das Prinzip Verantwortung. Versuch einer Ethik für die Technologische Zivilisation. Frankfurt am Main: Suhrkamp.

Knorr Cetina Karen (2002), Die Fabrikation der Erkentniss. Zur Anthropologie der Naturwissenschaften. Frankfunrt am Main: Suhrkamp.

Kristeva Julia (1998), El lenguaje, ese desconocido. Introducción a la lingüística. Madrid: Editorial fundamentos.

Laclau, Ernesto y Chantal Mouffe (1987), Hegemonía y estrategia socialista. Hacia una radicalización de la democracia. Madrid: Siglo XXI.

Latour Bruno (2007), Nunca fuimos modernos. Ensayo de antropología simétrica. Buenos Aires: Siglo XXI.

(2010), Das Parlament der Dinge. Frankfurt am Main: Suhrkamp Verlag.

(2004), Reensamblar lo social. Una introducción a la teoría del actor- red.

Buenos Aires: Manantial.

(2008), "Llamada a revisión de la modernidad. Aproximaciones antropológicas". En: Tomás Sánchez Criado (edit.). Technogénesis. La construcción técnica de las ecologías humanas. Vol. 2. Madrid: AIBR.

Laval Christian \& Dardot, Pierre. (2015), Común. Ensayo sobre la revolución en el siglo XXI. Barcelona: Gedisa.

Leff Enrique (2003), "La ecología política en América Latina. Un campo en construcción.” En Revista Sociedad e Estado. Brasilia. V. 18 n 1/2. P. 17-40. 
México D.F: Siglo XXI.

Leiss Whilliam (1974), The domination of Nature. New York: Beacon Press Boston.

Lewis Richard \& Lewontin Richard (2009), The dialectical biologist. AAKAR Books. Delhi.

Marcuse Herbert (1970 a.), El hombre unidimensional. Barcelona: Seix Barral. Barcelona.

(1970 b.) Triebstruktur und Gesellschaft. Frankfurt am Main: Suhrkamp.

Marx Karl (1962), Das Kapital. Erster Band. Berlin: Dietz

Morton Timothy (2007), Ecology without Nature. Harvard University Press, Cambridge, Massachusets, London.

Neil Aubrey (2007), How skeptics do ethics. A Brief history of the linguistic turn Calgary: Calgary Press.

Nietzsche Friedrich (1980), Jenseits von Gut und Böse. München: Carl Hanser Verlag.

Ostron Elinor (2000), El gobierno de los comunes. La evolución de las instituciones de acción colectiva. México D.F.: UNAM-CRIM-FCE.

Reynoso Carlos (2003), El surgimiento de la antropología postmoderna. Barcelona: Editorial Gedisa.

Rheinberger Hans-Jörg (2006), Experimentalsysteme und epistemische Dinge. Frankfurt am Main: Suhrkamp.

Rifkin Jeremy (1999), El siglo de la biotecnología. Barcelona: Crítica.

Rousseau Jean- Jaques (1982), El contrato social. Madrid: Edaf.

Rose Nikolas (2007), The Politics of life itself. Biomedizin, Power, and subjectivity in the Twenty-first century. Princeton: Princeton University Press.

De Sousa. Santos Boaventura (2013), Descolonizar el saber, reinventar el poder. Santiago de Chile: Ediciones Lom.

Saussure Ferdinand de (1945), Curso de lingüística general. Buenos Aires: Losada.

Secreto María Verónica (2011), "Ese comunismo estéril en que vegetan" El individualismo agrario frente a las formas ancestrales de propiedad y los usos tradicionales de la tierra". En: La naturaleza colonizada. Ecología política y minería en América Latina. Hector Alimonda (coordinador) CLACSO, Buenos Aires: Ediciones CICCUS.

Serres Michel (2004), El contrato natural. Valencia: Pre-Textos 
Shapin Steven \& Shaffer Simon (1985), Leviathan and the air pump. Hobbes, Boyle and the experimental life. Princeton/New Jersey. Princeton University Press.

Shiva Vandana (2003), ¿Proteger o expoliar? Los derechos de propiedad intelectual. Barcelona: Ediciones Octaedro.

Sibilia Paula, (2009) El hombre postorgánico. Cuerpo, subjetividad y tecnología digitales. Buenos Aires: F.C.E.

Sloterdijk Peter, (1999), Sphären II. Globen. Frankfurt am Main: Suhrkamp Verlag.

(2000) Reglen für den Menschenpark. Ein Antwortschreiben zu heideggers Brief über den Humanismus. Frankfurt am Main: Suhrkamp Verlag.

(2016) Was geschah im 20. Jahrhundert? Berlin, Suhrkamp.

Smith Neil. (2007), "Nature as accumulation strategy", (16-36). En: Socialist Register. № 43.

Stengers Isabelle (1997), Die Erfindung der Modernen Wissenschaften. Frankfurt am Main: Campus (2008), Spekulativer Konstruktionismus. Berlin: Merve

Sunder Rajan Kaushik (2006), Biocapital. The constitution of postgenomic life. Durham and London: Duke University Press.

Svampa Maristela (2016), "Extractivismo, desarrollo y buen vivir. Visiones en pugna". En: Intervenciones/Actuell Marx. №20 Primer semestre. Santiago de Chile: Lom ediciones.

Swyngedouw Eric (2011), "La naturaleza no existe. La Sostenibilidad como síntoma de una planificación despolitizada" (P. 41-66) Revista Urban 01.

Von Weizsäcker Carl Friedrich (1982), Der Garten des menschlichen. Beiträge zur geschichtlichen Anthropologie. München: Carl Hanser Verlag.

Weber Max (2004), La ética protestante y el espíritu del capitalismo. Buenos Aires: Ediciones Libertador.

Whilliams Raymond (1985), Nature“. En: Keywords. A vocabulary of culture and society. New York: Oxford University Press.

Wittgenstein Ludwig (1984), Philosophische Bemerkungen. Werkausgabe Band 2. Frankfurt am Main: Suhrkamp.

Zapata Silva Claudia (2016), Intelectuales indígenas en Ecuador, Bolivia y Chile. Diferencia, colonialismo y anticolonialismo. Santiago de Chile: Lom

Declaraciones de conferencias y foros internacionales sobre el desarrollo sostenible y el medio ambiente. 
Declaración de Rio sobre el medio ambiente y el desarrollo. Rio de Janeiro 1992.

www.un.org.

Declaración de Johannesburgo sobre el desarrollo sostenible. Desde nuestro origen hasta le futuro. 2002. www.un.org

El futuro que queremos. Documento final conferencia Rio +20 . Conferencia de las Naciones Unidas sobre el desarrollo sostenible.

www.un.org

Página oficial del consejo económico y social de las naciones unidas.

https://www.un.org/ecosoc/es/ 